\title{
Conscientious Objector: Pacifism, Politics and Abusing the Player in Doom 3
}

\author{
Dan Pinchbeck* \\ Thechineseroom, University of Portsmouth, Eldon Building, \\ Winston Churchill Avenue, Portsmouth, UK \\ dan.pinchbeck@port.ac.uk
}

\begin{abstract}
This paper describes Conscientious Objector, a research mod built using the idTech4 engine and assets from the commercial game Doom 3. It was designed to explore the potential for non-lethal force in FPS gaming, and player response to a radically different avatar-NPC relationship.
\end{abstract}

Keywords: Game, first-person shooter, Doom 3, development-led, modding, pacifism, non-player character.

\section{Introduction}

Conscientious Objector started life as a simple question: is it possible to build an FPS that removes the ability of the player to actually kill anything whilst retaining the fundamental playability of the game?

FPS games are defined by both the miminal representation of an avatar, and by the essential act of lining up objects with the centre of the screen and delivering an input. This function generally removes the object from the environment. Play thus becomes a process of simplifying the environment until it reaches a critical point, triggering progression. Put more simply, when there is nothing left to kill and no buttons left to press, it's time to move on. All FPS games work to this basic template, whether agents are released en masse in an arcade style, such as Painkiller [1], or there are attempts to model a more 'realistic' set of agent-environment relations, like S.T.A.L.K.E.R. [2]. We wanted to attempt to break this normal template and produce an environment that becomes progressively more complex as play progresses. The most obvious way of doing this has the equally interesting side-effect of breaking the other fundamental rule of FPS play, which is killing anything that moves.

Stopping the player from achieving this thus does two things at once: subverts the normal politics of the genre on one hand and establishes a radical new ludic structure on the other.

\footnotetext{
* Please note that the LNCS Editorial assumes that all authors have used the western naming convention, with given names preceding surnames. This determines the structure of the names in the running heads and the author index.
} 


\section{Rubber Bullets in UAC Admin}

Several pre-existing levels of the commercial game Doom 3 were re-configured for the mod. These were stripped of triggers, agents and objects in preparation for the new gameplay to be levered in. UAC Admin, Mars City and Mars City Underground were chosen as they were small and linear, with the kind of enclosed spaces with limited visibility that would play to the strengths of gameplay designed to engineer as much panic in the player as possible. Without introducing additional items, enough disparity could be introduced into these levels to maintain a sense of progressive gameplay. Additionally, we removed the oxygen from Mars City to introduce a temporal constraint on the player's activities: they were forced to run from oxygen cylinder to cylinder. Using known levels also enabled us, through voice-overs and embedded PDAs, to play a new political dimension off the already existing backdrop of corporate greed and fetishisation of the military.

The damage capacity of the shotgun was reduced to zero, whilst retaining its ability to knock down agents (a simple re-jig of the normal 'getting up' animation found on the basic zombie model). The time this sequence took to run, alongside a reduction in the bounding box and the knock-back effect of a succesful hit, meant that zombies could be effectively blown out of the player's way, giving them time to avoid the agent. Clearly, we are not the first to utilise non-lethal force (NLF) objects in an FPS game: Duke Nukem 3D had both Shrink and Freeze rays [3], Half Life 2's gravity gun occupies a central place in gameplay [4] and, famously, Deus Ex can allegedly be completed using NLF alone [5] - and an early beta of Doom 3 itself featured zombies that could only be permanently killed with a shot to the head. However, in all of these cases, NLF is a supplementary gimmick to core gameplay, rather than a centralised option. Indeed, in the case of Half Life 2, the gravity gun's main use is to hurl distinctly lethal objects like buzzsaw blades, barrels and cars, so it arguably doesn't really count. Likewise, Duke Nukem's ray guns are really there as a means to inflicting a fun coup-de-grace by stamping on or shattering enemies respectively, the latter revived recently by Bioshock [6]. Deus Ex does offer a way for the player to opt for NLF but it may be argued, that this is a niche configuration of gameplay at most. Thus, Conscientious Objector stands as the first FPS system to anchor gameplay directly to NLF. Further, although it may be argued that the mod does not represent a full game, the potential for drawing upon the range of NLF objects already existing in the genre is self-evident, and their addition would easily provide enough diversity of play to maintain the conceit. Indeed, we hope to one day extend Conscientious Objector to the entire of Doom 3 to prove just this. At this stage, however, we will settle for the proof of concept.

\section{Politics and Pacifism}

We can discuss the politics of FPS games on two levels - the surface and the underlying. In the former case, there is certainly more diversity now than there perhaps used to be. Avatars are still dominantly individualistic libertarians, fighting bureaucracy as much as aliens and demons, and the big businesses and industrial-political complexes and corporations are still corrupt and treacherous, but titles such as Bioshock, S.T.A.L.K.E.R. and 
Blacksite [7] are attempting to broaden the political spectrum. Although there is yet to be a return to the more open political and moral choices of the Deus Ex series, Bioshock offers the player the choice of killing or saving the Little Sisters, and Far Cry 2 [8] embeds the consequences of player actions in its world. Likewise, S.T.A.L.K.E.R.'s range of seven endings is based upon political choices the player makes during the game, although to be fair, most of these are not obvious during play. One could also argue that whilst saving the world is nothing new, and revenge following a betrayal by a key nonplayer character (KNPC) is close to ubiquitous, advances in AI and storytelling have personalised the actions of the player. Half Life 2: Episode Two sees the player fighting to save not millions of lives, but just one; the KNPC Alyx Vance. The very fact that the player is given clear and unambiguous indications that they are supposed to care about Vance and her father is a long way down the road from the faceless, nameless and disposable masses populating earlier games such as Halo (however, it should be noted that alongside saving humanity, the Master Chief is on an equally personal mission to save Cortana in the final installment of the trilogy). Personal motivation, particularly of the protective type, demonstrate a more mature political instinct at work than in early FPS games such as Doom, Quake and Duke Nukem.

However, behind all this increase in sophistication, FPS genres are constructed around a very simple and inflexible political core determined by the central act of gameplay. As John Carmack succinctly put it: "You can dress it up in many ways, but the game still comes down to: go here, touch this, go there, fight..." [9]. Rather than becoming wrapped up in the politics of violence and the endless discussions of social and psychological impact, the fact remains that FPS games are predicated around the removal of objects from a simplifying environment. Every action in the game is based upon this ludic format. By removing the player's ability to kill - that is, remove - anything, this template is fundamentally shifted, and with it the underlying politics of the game. Once again, it is hoped that with this practical example, we have proved it can be done in a way which critiques the normal surface whilst retaining high focus on gameplay. In other words, it may be a gimmick, but it is a highly playable one.

\section{Carl - Abusing the Player}

These changes naturally led to the third axis of experimentation in the mod, an abrupt shift to the normal relationship between player and KNPC. There are a number of expected features of this relationship one finds across the genre. Some, like the betrayal of the avatar by the KNPC are functions of extended gameplay, operating as a device enabling both revised interpretation of prior action (thus extending the narrative range of the game) and, in some cases, enabling a virtual increase in complexity without requiring additional assets to be generated. For example, Doyle's betrayal in the last section of Far Cry [10] means that whilst more or less exactly the same course of action is followed by Carver, the emphasis has changed from escape to revenge, the target of the goal has moved from Kreiger to Doyle, and there is a (fake) temporal constraint created by the infection of Carver and Val with the Trigen mutagen. None of this is real, of course, unlike the actual countdown of The Maw, Halo's last level [11] but it does enable players looking for a deeper ludic reality something to get their teeth into. However, regardless of betrayals, KNPCs such as Cortana, or Alyx Vance 
tend operate as both orientation devices and feedback systems, letting the player know where to go and whether they are acting effectively. This naturally leads towards certain semantic representations, archetypical characters and avatar-KNPC relationships. In Conscientious Objector, we saw an opportunity to subvert these expectations as well. Hence, the game opens with the aggressively cheerful "morning dickhead!"' and ends with Carl, the KNPC triggering the cranial implant that will kill the player as soon as they acheive their goal (he meets the players success and forces what would normally be considered a failure outcome upon them).

Carl operates as the normal political voice of FPS games: reminding the player frequently that they have no power or ability to make decisions, that killing things is both easy and rewarding and pointing out how much more difficult not being able to carry this normal activity out makes the process. Because of his antagonistic position, it also gave us the opportunity to explore pushing the KNPC into as hostile a position as possible. Carl taunts and mocks a successful act as much as a failed one; when the player misses a zombie, they are berated as useless; when they hit one, Carl is quick to point out how little effect it has. In doing so, the frustrations of gameplay find a locus in Carl, the irony being that by the end of play the urge to really, actually shoot someone has been personalised in his direction. Rather than a betrayal creating a forced nemesis, revenge becomes a distinctly localised matter. And, of course, the fact that Carl is openly repellent, coupled with his constant insistence that if only the player acted like an avatar in a normal FPS game would - by killing everything that moved - they would be successful, creates a much more interesting political dynamic in the mod.

\section{Conclusion}

Conscientious Objector aims to radically break the normal template for FPS play by removing the core act of play: removing objects from the environment. From this deceptively simple start, a range of interesting shifts to expected play naturally fall into line. The underlying politics of gameplay is questioned and thrown into relief, and a new type of player-KNPC relationship is created. But perhaps above all of these experiments, the overriding concern was to create a mod that both explores research questions in a way that simple theorising cannot, and remains a highly playable experience. That is to say, it also stands as an argument that gameplay and research are wholly compatible.

\section{Acknowledgments}

Conscientious Objector was built as part of thechineseroom, a development-led research project funded by the Arts\&Humanities Research Council, UK.

\section{References}

1. People Can Fly: Painkiller. Activision, PC (2005)

2. GSC Game World: S.T.A.L.K.E.R.: Shadow of Chernobyl THQ / GSC, PC (2007)

3. GT Interactive: Duke Nukem 3D 3D Realms, PC (1996) 
4. Valve: Half Life 2 Valve, PC (2004)

5. Ion Storm: Deus Ex Eidos Interactive, PC (2007)

6. 2K Games Bioshock 2K Games, PC (2007)

7. Midway: Blacksite: Area 51 Midway, PC (2007)

8. Ubisoft Montreal: Far Cry 2 Ubisoft, PC (2008)

9. Kushner, D.: Masters of Doom. Piatkus (2003)

10. Crytek: Far Cry Ubisoft, PC (2000)

11. Bungie: Halo: Combat Evolved Microsoft Game Studios, XBox (2007) 